\title{
THE IMPACT OF SENSITIVE SKIN ON THE QUALITY OF LIFE
}

\author{
Filka Georgieva, Joanna Velevska, Tsveta Kalinova, Valentina Brostilova \\ Department of Dermatology and Veneorology, Faculty of Medicine, \\ Medical University of Varna
}

\begin{abstract}
INTRODUCTION: Sensitive Skin Syndrome (SSS) is officially defined as a syndrome with unpleasant sensations like itching, pain, and numbness in response to stimuli that usually do not cause such sensations. In most of the cases it is a self-defined condition without objective pathological findings. Few studies have underlined the influence of SSS on the quality of life (QoL). The main problem is that people with sensitive skin suffer both with and without topical or internal care, which puts them in an extremely complex position and still without a solution.
\end{abstract}

AIM: The aim of the study was to assess the impact of SSS on QoL.

MATERIALS AND METHODS: The presented study includes 304 females self-diagnosed with SSS. Demographic data and disease-related characteristics were collected. The measurement tools, for assessing Sensitive Skin included 10-item version of Sensitive Scale. For the evaluation of QoL Dermatological Life Quality Index (DLQI) a questionnaire was applied. Additionally, QoL of these patients was comparable to that of patients with hand eczema (HE) and those suffering from dermatoses accompanied by severe itch (Lichen simplex chronicus LSC).

RESULTS AND DISCUSSION: Results showed the overall frequency of SSS - 31.97\% with the following distribution $57.23 \%$ in aesthetic visitors and $42.77 \%$ in those with a health problem. The total DLQI score reported by the SSS-patients was $8.4 \pm 3.29$. Patients scores were significantly high for Q1 (feelings), Q2 (embarrassment), and Q3 (free time/leisure) $(\mathbf{p}<0=001)$.

CONCLUSION: All the reported and analyzed results indicate that SSS has a negative impact on most of the QoL-domains for every patient $(p<0.001)$. Consequently, sensitivity of skin moderately affects QoL of the patients. This is the first study in our country, which aims to measure the impact of sensitive skin on QoL of patients.

Keywords: sensitive skin, quality of life, Dermatology Life Quality Index

Address for correspondence:

Filka Georgieva

Faculty of Medicine

Medical University of Varna

55 Marin Drinov St

9002 Varna

e-mail:filka@abv.bg

Received: April 13, 2019

Accepted: June 5, 2019

\section{INTRODUCTION}

The official definition of sensitive skin is accepted by the International Forum for the Study of Itch (IFSI). This syndrome is determined by the appearance of unpleasant sensations (stinging, burning, pain, pruritus, and tingling sensations) in response to stimuli that usually do not cause such sensations (1). 
Filka Georgieva, Joanna Velevska, Tsveta Kalinova et al.

In 1987 Maibach used the term Cosmetic Intolerance Syndrome, describing the condition of increased skin sensitivity without any visible changes (2). The term "status cosmeticus" is later adopted (3). Literary and clinical observations show an increase in patients complaining of sensitive skin $(4,5)$. This is predominantly a self-diagnosis based entirely on the patient's history (6). The condition is provoked not only by cosmetic products but also by a number of environmental factors (7).

On the other hand the lack of objective indicators makes sensitive skin syndrome (SSS) difficult to study, analyze and predict. The necessity of this study is due to the increasing of its importance and the lack of an adequate approach to these patients.

For the purpose of the study, the quality of life (QoL) definition of the World Health Organization (WHO) is accepted as a theoretical frame: "Quality of life is defined as individuals' perceptions of their position in life in the context of the culture and value systems in which they live and in relation to their goals, expectations, standards and concerns. It is a broad-ranging concept affected in a complex way by the persons' physical health, psychological state, and level of independence, social relationships and their relationship to salient features of their environment (8).

\section{AIM}

The aim of the study is to assess the impact of sensitive skin on QoL of patients' by evaluating the degree of sensitive feeling of the skin and compare it with the results from the answers to a standardized dermatology-specific quality of life instrument - Dermatological Life Quality Index (DLQI). Additionally, QoL of these patients was comparable to that of patients with hand eczema (HE) and those suffering from dermatoses with severe itch as lichen simplex chronicus (LSC).

\section{MATERIALS AND METHODS}

\section{Settings and Sample}

To assess the tendencies in distribution of SSS data from registers of Medico-Aesthetical Centre "Medea" Varna collected from April 2017 till April 2019 were analyzed. Data included reports of $972 \mathrm{fe}-$ male visitors at a mean age $43.17 \pm 14.45$ years (range 22-68 years) with different skin or aesthetic prob- lems. The diagnosis of SSS was self-assessed in 304 cases (31.97\%); 174 (57.23\%) aesthetic visitors and 130 (42.77\%) with health problem.

\section{Methods}

Patients were asked to record their current skin sensitivity using the 10-item version of Sensitive Scale. Just like the problem of SSS, this scale is relatively new and exists in a 14 -item and a 10 -item variants (9-10). The Sensitive Scale-10 was the dermatology-specific instrument developed by a group of 4 experts. It comprises 10 items, giving a sum score ranging between 0 and 140.The skin irritability is measured from 0 to 10 by a visual analog scale. This validated self-assessment questionnaire has been used in many epidemiological studies of SSS in different countries and is available in English, Chinese, Portuguese, Spanish and Italian languages (11-12). For the purpose of our study the 10 item Sensitive Scale was translated into Bulgarian.

To evaluate the influence of sensitive skin on patients' QoL the DLQI is applied. DLQI is the first dermatology-specific QoL instrument developed in 1994. DLQI comprises 10 items, giving a sum score ranging between 0 and 30. Ten questions (Q1 to Q10) concerning symptoms, embarrassment, shopping/ daily activities, clothes, and social/leisure. This validated questionnaire has been used in over 40 different skin conditions in over 80 countries and is available in over 90 languages. Its use has been described in more than 1000 publications including many multinational studies. The DLQI is the most frequently used instrument in studies of randomized controlled trials in dermatology. High DLQI scores imply low QoL (13).

An individual DLQI-instrument was provided to the patients during the routine consultation. Every patient was given oral instructions on how to fill out the questionnaire.

Patients gave written informed consent for clinical data collection and analysis.

For the purpose of comparison of patients with $\mathrm{HE}$ and those suffering from dermatoses with severe itch (LSC) the results from our previous studies were used (14-15).

The statistical analysis was performed with SPSS v.21.0 for Windows. Hypotheses were tested using $\chi^{2}$-criteria (for the descriptive profile data). Re- 
sults with $\mathrm{p}<0.001$ were interpreted as statistically significant.

\section{RESULTS}

Results showed that the overall frequency of SSS was 31.97\%. Among them 174 (57.23\%) were visitors with aesthetic problems and $130(42.77 \%)$ with a health problem. A total of 164 (53.94\%) reported having "sensitive skin" and 140 (46.06\%) "very sensitive".

According to the results achieved in a recent study the DLQI score for SSS was $8.4 \pm 3.29$ (medi-
Among patients with SSS, there were high score for Q1 (feelings), Q2 (embarrassment), Q3 (free time/leisure), Q6 (sport) and Q7 (job).

Scores for the six domains were compared as well (Table 2). DLQI scores were significantly high for all domains except for domain 5 (personal relationship)

The DLQI score for LSC was $8.58 \pm 3.29$ (median 8.00; IQR 3.00-19.00) (14). The DLQI score for HE was 10.3 \pm 4.19 (median 11.00; IQR 4.00-26.00) (15). Exact comparative rating data are given in Table 3.

Table 1. Scores of the answers of the 10 Questions

\begin{tabular}{lccc}
\hline Question & median & range & p-value \\
Q1 feelings & 3.00 & $2.00-3.00$ & $<0.002$ \\
Q2 embarrassment & 3.00 & $2.00-3.00$ & $<0.001$ \\
Q3 daily work, at home, garden & 1.00 & $1.00-2.00$ & $<0.001$ \\
Q4 choosing cloths & 0.00 & $0.00-0.00$ & $<0.001$ \\
Q5 free time, leisure & 2.00 & $0.00-2.00$ & $<0.001$ \\
Q6 sport & 1.00 & $0.00-1.00$ & 0.113 \\
Q7 job & 1.00 & $2.00-3.00$ & $<0.002$ \\
Q8 relationship & 0.00 & $0.00-0.00$ & 0.146 \\
Q9 sex & 0.00 & $0.00-0.00$ & $<0.003$ \\
Q10 treatment & 1.00 & $0.00-1.00$ & $<0.003$ \\
\hline \hline
\end{tabular}

an 10.00; IQR 4.00-24.00). Therefore SSS affects the QoL of the patients in a mild to moderate way. A total of 158 (51.97\%) scored between 2 and 5. Almost an equal number had a score between 6 and $10-124$ individuals (40.78\%). Furthermore, 22 (7.25\%) of the patients scores were between 11 and 20. Scores for the DLQI are given in Table 1. The patients with SSS had significantly high scores for all items $(\mathrm{p}<0,001)$ except for Q4 (cloths), Q8 (relationship) and Q9 (sex).
Table 2. Distribution of six domains

\begin{tabular}{lc|cc}
\hline Domain & Median & Range & p-value \\
Symptoms and feelings & 4.00 & $3.00-6.00$ & $<0,001$ \\
Daily activities & 2.00 & $2.00-5.00$ & $<0,001$ \\
Leisure & 4.00 & $3.00-6.00$ & $<0,001$ \\
Work/School & 2.00 & $1.00-4.00$ & $<0,001$ \\
Personal relationship & 0.00 & $0.00-0.00$ & $<0,001$ \\
Treatment & 1.00 & $0.00-2.00$ & $<0,001$ \\
\hline
\end{tabular}

Table 3. Comparative rating data according to the DLQI score

\begin{tabular}{lc|cc} 
Range of Score & SSS & LSC (Pruritus) & Hand Eczema \\
$0-1$ no influence & $0 / 0$ & $0 / 0$ & $0 / 0$ \\
$2-5$ mild & $158 / 51.97$ & $32 / 16.8$ & $5 / 6.41$ \\
6-10 moderate & $124 / 40.78$ & $110 / 57.9$ & $38 / 48.72$ \\
$11-20$ high & $22 / 7.25$ & $48 / 25.3$ & $21 / 26.92$ \\
$21-30$ very high & $0 / 0$ & $0 / 0$ & $14 / 17.95$ \\
Total & $304 / 100$ & $190 / 100$ & $78 / 100$ \\
\hline \hline
\end{tabular}


Filka Georgieva, Joanna Velevska, Tsveta Kalinova et al.

Comparative scores of the answers of the 10 item questionnaires are given in Table 4.

Table 4. Comparative scores of the answers of the 10 Questions

\begin{tabular}{llll}
\hline Question & SSS & HE & LSC \\
Q1 feelings & 3.00 & 2.00 & 2.00 \\
Q2 embarrassment & 3.00 & 2.00 & 2.00 \\
Q3 daily work, at home, garden & 1.00 & 1.00 & 0.00 \\
Q4 choosing cloths & 0.00 & 0,00 & 1.00 \\
Q5 free time, leisure & 2.00 & 1.00 & 1.00 \\
Q6 sport & 1.00 & 0.00 & 0.00 \\
Q7 job & 1.00 & 3.00 & 1.00 \\
Q8 relationship & 0.00 & 0.00 & 0.00 \\
Q9 sex & 0.00 & 1.00 & 1.00 \\
Q10 treatment & 1.00 & 1.00 & 2.00 \\
\hline \hline
\end{tabular}

Comparative rating data according to DLQIdomains is illustrated on Fig. 1.
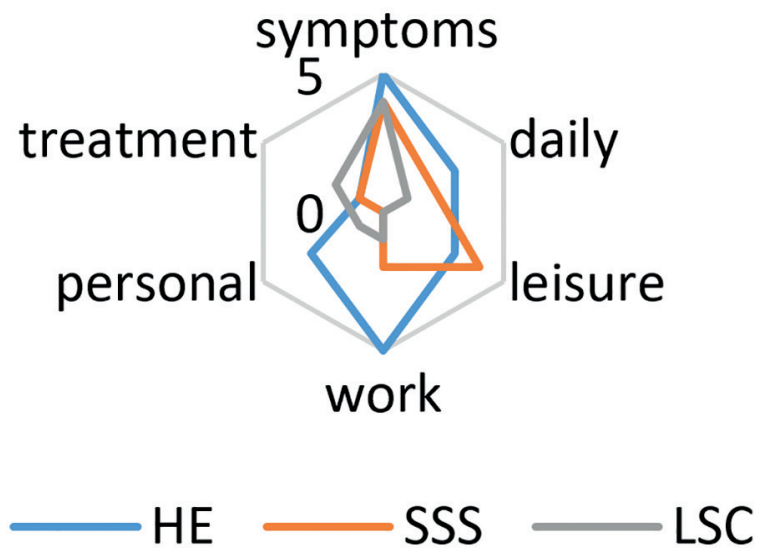

Fig. 1. The distribution of pattern score according to the DLQI domains

\section{DISCUSSION}

Researchers suggest that SSS has a negative impact on QoL (16-18). Misery et al. (2005) investigated 1001people and published that $20.7 \%$ were selfdiagnosed as "very sensitive", and $38.2 \%$ as "sensitive". The authors pointed out the correlation in the sensitivity, and the negative impact on the QoL (17). Our results have shown that in all patients who define their skin as sensitive or very sensitive, QoL is mildly to moderately impaired $-8.4 \pm 3.29$ (median 10.00; IQR 4.00-24.00). It is obvious that feelings (Q1) (stinging, burning, pain, pruritus, and tingling sensations) and daily activities (Q3) are negatively influenced whether in leisure (Q5) or in the work environment (Q7).

However, despite the increasing number of publications related to this syndrome, we have not found many specific research on this issue. Because of this, we compared the influence of sensitive skin on QoL with other dermatoses for which we assumed that there was a similar spectrum of subjective complaints. HE cause domestic, psychological, social and occupational undesirable outcomes (15,19-21). Patients with HE showed higher scores for QoL and it was pointed out that $\mathrm{HE}$ affected mostly the domains of symptoms and feelings (mean 5.00) and work/school (mean 5.00) (15). Numerous studies with a 30item DLQI questionnaire detected deterioration of QoL in LSC patients (14, 22-24). Severe itching is a prominent feature of LSC that is why domain 1 (symptoms and feelings) had the biggest impact on LSC patients (mean 2.00) (14).

Pruritus is a common symptom in both LSC and SSS. On the other hand, dryness, stinging and constant discomfort are common sensations for HE and SSS. And though LSC and HE are chronic dermatoses patients have temporary relief after properly treatment. A number of studies have shown that the condition of sensitive skin gets worse in the process of therapy $(25,26)$. This could be one of the explanations for comparable quantitative indicators in measuring QoL as well as the prevalence of the impact on the domain of symptoms and feelings

The lack of studies on the influence of SSS on QoL gives us reason to believe that this is the first study on this topic.

\section{CONCLUSION}

The present study is focused on the influence of SSS on QoL of patients and slightly investigate some epidemiological aspects of these skin condition. SSS affects negatively the QoL of the patients. Therefore, a study of their self-reported health status alongside with the clinical investigation is a necessary precondition for successful therapeutic results. There was a limitation in this study as far as sensitivity of the skin and QoL of patients were assessed once and not in dynamics, before and after treatment. 


\section{REFERENCES}

1. Misery L, Ständer S, Szepietowski JC, Reich A, Wallengren J, Evers AW, et al. Definition of sensitive skin: An expert position paper from the special interest group on sensitive skin of the International Forum for the Study of Itch. Acta Derm Venereol. 2017;97(1):4-6. doi: 10.2340/00015555-2397.

2. Maibach HI. The cosmetic intolerance syndrome. Ear Nose Throat J. 1987; 66(1):29-33.

3. Fisher AA. "Status cosmeticus": a cosmetic intolerance syndrome. Cutis. 1990; 46(2):109-10.

4. Taieb C, Auges M, Georgescu V, Perez Cullell N, Miséry L. Sensitive skin in Brazil and Russia: an epidemiological and comparative approach. Eur J Dermatol. 2014; 24(3):372-6. doi: 10.1684/ ejd.2014.2367.

5. Willis CM, Shaw $S$, De Lacharrière $O$, Baverel M, Reiche L, Jourdain R, et al. Sensitive skin: an epidemiological study. Br J Dermatol. 2001; 145(2):258-63. doi: 10.1046/j.1365-2133.2001.04343.x.

6. Berardesca E, Farage M, Maibach H. Sensitive skin: an overview. Int J Cosmet Sci. 2013; 35(1):2-8. doi: 10.1111/j.1468-2494.2012.00754.x.

7. Lev-Tov H, Maibach HI. The sensitive skin syndrome. Indian J Dermatol. 2012; 57(6):419-23. doi: 10.4103/0019-5154.103059.

8. WHO. WHOQOL-BREF - Instructions, Administration, Scoring and Generic Version of the Assessment. WHO. Geneva; 1996-5.

9. Misery L, Jean-Decoster C, Mery S, Georgescu $\mathrm{V}$, Sibaud V. A new ten-item questionnaire for assessing sensitive skin: the Sensitive Scale-10. Acta Derm Venereol. 2014; 94(6):635-9. doi: 10.2340/00015555-1870.

10. Misery L, Jourdan E, Abadie S, Taied C. Development and validation of a new tool to assess the Burden of Sensitive Skin (BoSS). J Eur Acad Dermatol Venereol. 2018;32(12):2217-23. doi: 10.1111/jdv.15186.

11. Richters R, Falcone D, Uzunbajakava N, Verkruysse W, van Erp P, van de Kerkhof P. What is sensitive skin? A systematic literature review of objective measurements. Skin Pharmacol Physiol. 2015; 28(2):75-83. doi: 10.1159/000363149.

12. Duarte I, Silveira J, Hafner M, Toyota R, Pedroso D. Sensitive skin: review of an ascending concept.
An Bras Dermatol. 2017 J; 92(4):521-5. doi: 10.1590/ abd1806-4841.201756111.

13. http://sites.cardiff.ac.uk/ dermatology/quality-of-life/ dermatology-quality-of-life-index-dlqi

14. Georgieva F, Vankova D, The impact of pruritus on quality of life of patients with lichen simplex chronicus. Scr Sci Med. 2016;48(2):50-4. doi:10.14748/ssm.v48i2.1591.

15. Georgieva F. Hand eczema and its impact on wellbeing and quality of life of patients. JIMAB. 2017; 23(1):1490-4.

16. Misery L. Sensitive Skin: Do we observe an impact on quality of life? In: Honari G, Andersen R, Maibach HL, editors. Sensitive Skin Syndrome. 2nd Edition. Taylor \& Francis Group; 2017.

17. Misery L, Myon E, Marionneau N, Taieb C. Sensitive skin: impact on quality of life. Value Health ISPOR. 2005; 8(6):A149.

18. Misery L, Loser K, Stander S. Sensitive skin. J Eur Acad Dermatol Venereol. 2016;30(Suppl 1):2-8. doi: 10.1111/jdv.13532.

19. Safizadeh H, Shamsi-Meymandy Sh, Narsi L, Shamsi-Meymandy M. Quality of life among patients with hand eczema in Iran. Russ Open Med J. 2013; 2(3):1-4.

20. Thyssen JP, Johansen JD, Linneberg A, Menné T. The epidemiology of hand eczema in the general population-prevalence and main findings. Contact Dermatitis. 2010; 62(2):75-87. doi: 10.1111/j.1600-0536.2009.01669.x.

21. Coenraads PJ. Hand eczema is common and multifactorial. J Invest Dermatol. 2007; 127(7):156870. doi: 10.1038/sj.jid.5700781.

22. Root S, Kent G, Al Abadie MSK. The relationship between disease severity, disability and psychological distress in patients with lichen simplex chronicus. Dermatology. 2013;189:234-7.

23. Hamed El-Maadawy I, Ahmad El-Ashmawy A, Hoedib A. Impact of some chronic dermatoses on Quality of Life of Egyptian patients in Delta Region. Egypt Dermatol Online J. 2014; 10(1):1-23. doi:10.12816/0025591.

24. An JG, Liu YT, Xiao SX, Wang JM, Geng SM, Dong YY. Quality of life of patients with neurodermatitis. Int J Med Sci. 2013;10(5):593-8. doi: 10.7150/ ijms.5624. 